\title{
Heidegger e Agostinho: o fenômeno da tentatio E A HISTORICIDADE DO SI (SELBST) NA APROPRIAÇÃO FENOMENOLÓGICA DO LIVRO X DAS CONFISSÓES
}

\author{
Bento Silva Santos ${ }^{1}$
}

\begin{abstract}
Resumo: $\mathrm{O}$ artigo trata do fenômeno da cura segundo a apropriaçáo fenomenológica do livro X feita por Martin Heidegger no curso friburgense intitulado Augustinus und der Neuplatonismus (SS1921). Pretendemos apresentar o fenômeno da tentação e a historicidade do si: segundo a apropriação genuína do ser da vida de Agostinho, a "tentatio" (Versuchung) se torna expressão da mobilidade da existência histórico-atuativa, que jamais pode ser compreendida como "quietude". É a vida mesma que, assumida em sua totalidade, representa uma "tentação", uma provação - entendida em sentido ontológicoexistencial - na medida em que indica o "como" (Wie) da atuaçáo da facticidade. Na procura deste "como" originário surge a interrogação fundamental do que vem a ser a vida para si mesma: quaestio mihi factus sum ( $f i z$ de mim mesmo uma questäo). Descortinamos na perda de si do "eu sou" o processo da temporalização como deformitas, como o defluxus na distração, como a queda no "inautêntico". Com base nesta apropriaçáo contemporânea do ser da vida de Agostinho chegaremos ao âmago do fenômeno da cura, compreendendo o curare como caráter fundamental da vida fática e reconhecendo na procura de Deus a constituiçáo da facticidade e da cura de si que nesta procura se expressa.
\end{abstract}

Palavras-Chave: Cura. Vida. Fenomenologia. Cristianismo das origens. Facticidade.

\section{INTRODUÇÃo}

Apresentar a profunda relação entre a dimensão histórica da vida e o fenômeno da tentatio, em contraposiçáo à tendência de interpretar tal tensão em sentido axiológico, é o desafio que Martin Heidegger se colocou na preleção acadêmica do semestre de verão de 1921 (HEIDEGGER, 1995, p. 158-246); ver sobretudo BRITO MARTINS, 1998) ao reler

\footnotetext{
${ }^{1}$ Professor Titular no Departamento de Filosofia, Universidade Federal do Espírito Santo (UFES), Vitória, ES - Brasil. (D) https://orcid.org/0000-0001-6111-1693 E-mail: benedictus1983@yahoo.com.br

Coordenador do Programa de Pós-Graduação em Filosofia (Mestrado /Doutorado) da UFES. Bolsista de Produtividade em Pesquisa, Nível 02, do CNPq.
}

http://dx.doi.org/10.1590/0101-3173.2019.v42esp.08.p135 
fenomenologicamente o livro X das Confissóes, onde $\mathrm{Agostinho}^{2}$, confessando a própria debilidade e insegurança, se questiona acerca de suas forças e duvida se poderá confiar em si mesmo. É assim que Heidegger tratará da experiência histórica na medida em que a vida é uma ininterrupta provação, na qual o si-mesmo pode, dispersando-se no tempo, possuir a possibilidade da gestão autêntica do ser da vida:

$\mathrm{Na}$ atuaçáo concreta e autêntica da experiência, o si se dá a possibilidade da queda (Abfall), mas ele se dá ao mesmo tempo, na preocupação concernente ao ser de si mesmo (Selbstbekümmerung) mais próprio e mais radical, a 'ocasião' (Gelegenheit) plenamente concreta e fática de encontrar o ser (Sein) da vida mais próprio. (HEIDEGGER, 1995, p. 244).

Portanto, com base nesta coesão entre historicidade do si e a tentatio, a vida concreta se exibe faticamente como "fardo", "peso" e até mesmo como sendo angustiante, o que confirma que esta mesma existência deve manter-se na possibilidade mais radical da queda e, ao mesmo tempo, na ocasiáo de conquistar a si mesmo. Neste sentido, a chave para compreender o autêntico sentido da historicidade da existência reside na incerteza e na indeterminação do não saber de onde está a vitória: "A experiência - é ela que descobre a tentatio, mas nescio [ignoro] o que será.” (HEIDEGGER, 1995, p. 252). O fato de não ser possível prever o que acontecerá deve se tornar motivo de abertura diante das possibilidades e náo ocasião para esconder a si mesmo e voltar a ocultarse na própria vida em um "trancamento" (die Abriegelung) (HEIDEGGER, 1995 , p. 252), justamente porque este fenômeno apenas mencionado aqui na prelação sobre Agostinho significa que a vida fática traz sempre máscaras (Maskierung) (HEIDEGGER, 1985, p. 107), caracterizando-se como infinitas justamente porque ela não consegue dominar o "sempre-mais vida": a vida fática, portanto, necessita "disfarçar-se" não somente para esconderse, mas, antes de tudo, para proteger-se: "Essa infinitude é a máscara que a vida fática impóe e se representa faticamente a si mesma, isto é, a seu mudo." (HEIDEGGER, 1985, p. 107). É justamente no traço do "trancamento", fenômeno tratado especialmente em "Interpretaçóes fenomenológicas sobre Aristóteles" (WS 1920-1921) (GA 61) (HEIDEGGER, 1985, p. 1-155) que descortinamos a dimensão fenomenológica do acesso à minha existência através da tentação, no sentido de que, o ser tentado implica um trazer a vida

2 Sobre Heidegger e Agostinho, cf., entre outros, sobretudo (BRITO MARTINS 1998; GREISCH, 2000, p. 219-251; ESPOSITO, 2010; DAHLSTROM, 2010; SOMMER, 2011; COYNE, 2011; ARDOVINO, 2016, p. 221-239) (com ampla bibliografia). 
à demonstração como atuação do ser da vida fática, enquanto abrir-se a cada vez em sua facticidade para ora conquistar-se, ora perder-se.

Para mostrar a atualidade de Agostinho no pensamento contemporâneo, faremos (1) algumas consideraçóes preliminares sobre a leitura fenomenológica das Confissóes, para, em seguida, (2) examinar o sentido da tentatio com base na explicação hermenêutica enquanto atuação histórica ou, precisamente, "no que pertence à minha facticidade, isso que está comigo e onde eu sou, espreita a tentação. 'Ela está aí historicamente'." (HEIDEGGER, 1995, p. 252). A experiência enquanto histórica corresponde ao ser tentado e, portanto, em razão de seu pleno sentido nessa facticidade plena, no meu "eu sou" sou remetido a um futuro aberto e indeciso.

\section{Apropriaçáo fenomenológica das Confissóes de Agostinho: autobiografia E CONCENTRAÇÁO PARADIGMÁTICA NA EXPERIÊNCIA DO SI (SELBST)}

Depois de examinar as cartas de Paulo no semestre de inverno de 1920-1921 com a preleção "Introdução à fenomenologia da religiáo" com base na "explicação" fenomenológica da experiência cristã da vida, Heidegger se volta para Agostinho de Hipona com outra preleçáo ministrada no semestre de verão de 1921, intitulada "Agostinho e o neoplatonismo". O pressuposto metodológico na releitura do livro $\mathrm{X}$ das Confissóes é o mesmo utilizado com os textos paulinos. Afastando-se de uma abordagem histórico-objetiva (objektgeschichtlich), Heidegger reitera mais uma vez o sentido históricoatuativo (vollzugsgeschichtlich) da fenomenologia. O caminho consiste em problematizar a interpretação histórico-objetivante da tradição teológicofilosófica (realizadas por Ernst Troeltsch, Adolf von Harnack e Wilhelm Dilthey, todas orientadas para construçóes teóricas da ideia de homem e da existência humana da vida) para descortinar uma genuína apropriação do ser da vida de Agostinho, tal como podemos constatar com base na crítica radical de Heidegger (1995, p. 167):

$\mathrm{Na}$ medida em que nestas concepçôes históricas o sentido dominante do "olhar interno" [Hinsicht] é um contemplar [Hinsehen] o objeto estando inserido em um contexto de ordenação histórica, objetivamente colocado, costumamos caracterizá-lo como enfoque histórico-objetivo. O que é representado possui o sentido da objetualidade da imagem objetivamente traçada, e as condiçóes de acesso se concentram no domínio do material de determinação correspondente. A determinação do objeto assim realizada em termos tão primários é a que sustenta inicialmente todas as valoraçóes e tomadas de decisão posteriores. 
A intenção de Heidegger é clara: apropriar-se positivamente do passado sem incorrer no risco de uma objetivação ou de uma subjetivaçáo. Ora, a crítica de Heidegger àqueles que inserirem um autor (no caso, Agostinho) em um contexto histórico-objetivo se assemelha mutatis mutandis a qualquer interpretação de tipo hermenêutico. Se toda interpretação é viciada pela escolha de um determinado ponto de vista, o que sucederia então no caso das interpretaçóes histórico-objetivas dos três modelos rejeitados por Heidegger? Simplesmente o risco de uma excessiva contextualização com a consequente descontextualizaçáo de um pensamento, bem como o risco de não captar a originalidade de um pensador na tentativa de fazê-lo corresponder forçosamente a uma realidade histórico-cultural estranha e distante. Consequentemente, elevar uma experiência absolutamente singular, como a de Agostinho, àquela da relação transcendental com Deus, ao nível da generalidade, considerando-a como um caso particular de uma renovaçáo do espírito, dos costumes e da cultura própria de determinado tempo significa esvaziar o valor fortemente individual com a qual tal experiência tinha sido vivida por Agostinho.

Apesar do caráter aporético das observações introdutórias do curso Agostinho e o neoplatonismo, Heidegger manifesta, porém, "uma primeira, mas decisiva, intenção de afirmar a distância que há entre a hermenêutica e a metodologia, ou a impossibilidade de reduzir a hermenêutica a mera técnica através da qual a verdade dos textos pudesse emergir com plena aderência ao contexto originário que os tinha gerado", afirma Georgia Zeami (2010, p. 137.135-136). Portanto, não será tanto o "conteúdo" da confessio teológica [o "que coisa" (Was) do confessar] que reterá a atenção de Heidegger, mas sobretudo a atuação temporal do seu modo de referir-se a tal conteúdo (o que do seu como): se trata do como (Wie) de uma procura de salvaçáo. No caso do percurso existencial de Agostinho nas Confissóes, neste ser como procurar, Heidegger descortina uma estrutura ontológica enquanto "preocupação" da vida. Mas como se desdobra, concretamente, esta confessio de uma vida que se perdeu e tenta reencontrar-se? Através de uma repetição "des-helenizante" da vida fática com base na concentração paradigmática na experiência do Selbst no Cristianismo das origens, tal como Heidegger o fizera já na preleção "Problemas fundamentais da fenomenologia" ao qualificar de paradigmática a experiência cristã originária: "O cristianismo como paradigma histórico pelo deslocamento do epicentro da vida fática para o mundo do si-mesmo." (HEIDEGGER, 1993, p. 61). As Confissóes de Agostinho constituem o documento de uma disposição autenticamente protocristã que se valida no crede ut intelligas, ou seja, em termos da tradução interpretativa de Heidegger 
em 1919-1920: "Viva teu si de maneira vivificante [lebe lebendig dein Selbst] e somente neste solo de experiência, da tua última e mais plena experiência do si, se constrói o conhecimento" ou ainda "o si, antes de poder conhecer, deve antes de tudo realizar-se na plena vida." (HEIDEGGER, 1993, p. 62.205). Portanto, as Confissóes narram confessando uma "história do si" (HEIDEGGER, 1993, 59: Geschichte des Selbst).

No livro X das Confissóes, Agostinho se ocupa com sua situação presente e confessa coram Deo e coram hominibus, através de orações e questionamentos, o que ele é agora. Assim procedendo, ele pratica uma "interpretaçáo de simesmo", ou seja, uma autointerpretação na qual o si se manifesta evidentemente problemático no mais alto grau, justamente porque a confessio náo se reduz a um mero repositório estilístico-retórico, mas porque Agostinho comunica todos os fenômenos na atitude (Haltung) do confiteri afrontando a tarefa de procurar e de possuir a Deus, ou seja, tarefa que indica inequivocamente para Heidegger a investigação ontológica de sua apropriação: a "facticidade" e a "preocupação" da vida, respectivamente. Nas Confissóes, trata-se de captar o puro crescimento temporal de uma vida que fala confessando-se, e aí o eu confessante aparece e desaparece, exibindo o si como desejo do Outro, enquanto objeto de amor. Nesse amor-confessado ("quid amo, cum te amo?") (Conf. X, 6), o Outro está ausente como conteúdo e referente objetivantes justamente porque está presente sob outra modalidade, a saber, só como o id ipsum, a vita vitae, o "interior intimo meo" (Conf. X, 27, 38): enquanto realidade imanente à vida a partir da experiência fundamental do si (e da atuação do si) que procura a Deus no meio de múltiplas tentaçóes e provas cotidianas. Portanto, o Outro está presente enquanto determina o movimento fundamental da vida de Agostinho para um "mais-viver" (ARDOVINO, 2016, p. 230-232). Nesse sentido, o afeto da esperança é fundamental, uma vez que possibilita orientar minha vida para o futuro e antecipar um ideal. Eu posso antecipar o ideal que é uma vida filosófica, e tal vida filosófica é entáo como a vida de minha vida fática, ou seja, a "vida verdadeira" (SOMMER, 2011, p. 177-178). É justamente o que Heidegger tem em vista ao dizer: "A tendência para a vita beata, não in re, mas in spe." (HEIDEGGER, 1995, p. 283).

Se o motivo do confiteri agostiniano é motivado com base na "questio mihi factus sum", compreende-se assim que a categoria do "coram Deo" seja o "lugar" agostiniano e (cristão) do conhecimento de si (GREISCH, 2000, p. 225). Nesse sentido, a interpretação do si-mesmo se exibe concretamente nesse diante de quem (wovor) se confessa - Deus - o horizonte que norteia o próprio 
interpretar do ser da vida, bem como "nos contextos de experiência que se referem ao mundo compartilhado [Mitwelt] e ao estado do saber concernente ao mundo circundante [Umwelt]" (HEIDEGGER, 1995, p. 247). É aqui então que se insere a categoria da confissão "diante dos homens", quer esses sejam os curiosos ávidos de conhecer a vida alheia (cf. curiosum genus ad cognoscendam vitam alienam), quer sejam aqueles homens aos quais a caridade abrirá os ouvidos à palavra de Agostinho e acreditarão nele (AGOSTINHO, Conf., $\mathrm{X}, 3,3)$. Aqui entâo emerge justamente o ser da vida de Agostinho enquanto se conhece faticamente no viver "diante de" - coram Deo et coram hominibus. São possibilidades de apropriação de seu ser mesmo na medida em que são significatividades do mundo vivido em múltiplas direçóes: ao si, a Deus e ao mundo do entorno.

Heidegger julga então que Agostinho descortinou uma relação ontológica autêntica com o ego, e tal relação representa o "valor independente" (HEIDEGGER, 1995, p. 57). Nesse sentido, Heidegger encontrou os meios conceituais para ultrapassar o erro de Descartes: "Vita [vida] não é uma mera palavra ou um mero conceito formal, mas uma conexáo estrutural que o próprio Agostinho percebeu, contudo, não com suficiente agudeza conceitual." (HEIDEGGER, 1995, p. 298). O "eu sou", exibindo-se nas Confissóes como nibil, está inteiramente distante do "questionamento epistemológico" do "cogito" de Descartes (HEIDEGGER, 1995, p. 298)³. A linguagem da confissão a Deus é uma linguagem interior que, enquanto feita ora no silêncio, ora no tumulto, é um também um grito dos afetos (tacetnim strepitu, clamat affectu); desse modo compreende-se que Deus, enquanto objetualidade da confissão de Agostinho, é a "face que se reflete no coração". A experiência do ser do "eu" está assim na plena facticidade, onde o conhecimento disso resultante é aqui a significatividade, categoria desprovida de todo conteúdo objetivante. Portanto, à luz da citação agostiniana - "obriga teu coração a pensar nas coisas divinas" -, Heidegger (1995, p. 289) conclui: "Deus não é fabricado, mas o si-mesmo se realiza na condição de realizaçáo da experiência de Deus. É na preocupação que visa a vida mesma do si que Deus está presente. Deus, tomado como objeto, no sentido da facies cordis, age na vida autêntica do homem”. Diante dessas consideraçóes não é difícil descortinar o interesse da fenomenologia hermenêutica de Heidegger por esta caracterização

\footnotetext{
${ }^{3}$ Para examinar com a devida propriedade a crítica de Heidegger ao pensamento epistemológico de Descartes, remeto para a obra fundamental de C. PERRIN, Entendre la Métaphisique. Les significations de la pensée de Descartes dans l'oeuvre de Heidegger (PERRIN, 2013).
} 
do conhecimento de si ou, no vocabulário heideggeriano, pelo mundo de simesmo (Selbstwelt).

A leitura do livro X das Confissóes, em seu aspecto de "destruição" das abordagens objetivantes de Agostinho na história do pensamento metafísico, contribuiu para a formação da hermenêutica da facticidade na medida em que Heidegger enfatiza a questão da autointerpretação para exibir a natureza autêntica da "posse do si-mesmo" (das Sich-selbst-haben): a certeza e a posse do si-mesmo estão arraigadas no eu como nibil, e o cuidado autêntico provém de certa nadificação religiosa do si (COYNE, 2011. p. 198.206). O acesso à religiosidade autêntica do si não surge de uma axiologização com a doutrina de Deus como summum bonum, nem tampouco através da procura da felicidade universal, mas na experiência do ser tentado enquanto mobilidade ontológica do ser da vida.

\section{A EXPERIÊNCIA DA TENTAÇÁO E A HISTORICIDADE DO SI}

Após destacar a ênfase dada à leitura existencial das Confissóes de Agostinho com base sobretudo nos $\$ \$ 7-10$ da preleçáo Augustinus und der Neuplatonismus, Heidegger aprofundará na sequência o problema da cura nos $\$ \$ 12-17$ pelas seguintes razóes: Em primeiro lugar, comentando o livro X, 1-39 das Confissóes, Heidegger chega ao âmago do fenômeno da cura, compreendendo o curare como caráter fundamental da vida fática e reconhecendo no quaerere Deum a constituição da facticidade e da cura de si que nesta procura se expressa (HEIDEGGER, 1995, p. 192.205). Na perspectiva da leitura genealógica dos cursos ministrados em Freiburg, Jean Greisch sugeriu com razão que foi a interpretação da experiência cristã das origens que terá conduzido Heidegger para o caminho do reconhecimento da cura como existenciário fundamental (GREISCH, 2000, p. 205). No mesmo sentido se posicionam igualmente Adriano Ardovino (1998, p. 119) e Guelfo Carbone (2017, p. 218): o confronto com a dimensão agostiniana da cura foi decisivo para o percurso que conduz à noção heideggeriana de Sorge, central em Sein und Zeit, particularmente no sentido de inquietude, fadiga, fardo, e especialmente a angústia (que, de certo modo, como anxietas e sollicitudo, é o sentido predominante assumido da cura nas Confissóes). Em segundo lugar, o fenômeno da cura se relaciona fundamentalmente com a transformação da fenomenologia da vida fática, ou seja, com a progressiva intensificação da análise do mundo do si-mesmo e da dimensão histórico-realizadora da existência. Daí 
os dois temas centrais sobre os quais se concentra Heidegger em sua releitura fenomenológica do livro X das Confissóes: a procura de Deus por parte de Agostinho e a determinação da essência do homem como cura ["procurar a vida" (Lebensuchen), "preocupação da vida” (Bekümmerung um Leben)] (HEIDEGGER, 1995, p. 195) e como tendência ao pecado. Na releitura fenomenológica de Heidegger, descortinamos na perda de si do "eu sou" o processo da temporalização como deformitas, como o defluxus na distração, como a queda no "inautêntico". Desse modo, a experiência da tentaçáo e a historicidade do si-mesmo se manifestam no fenômeno do cuidado, bem como nas diferentes modalidades da apropriação e da compreensão do si com a tríplice subdivisão das tentaçôes.

\section{A. O CURARE (ESTAR PREOCUPADO) COMO DIMENSÃO FUNDAMENTAL DA VIDA FÁTICA}

A realidade do si-mesmo se manifesta com toda intensidade na interpretação fenomenológica de "tentatio" (Versuchung) enquanto expressão da mobilidade (Bewegtheit) da existência histórico-atuativa, irredutível ao antitético "quies", o repouso característico da contemplação de Deus como summum bonum. $\mathrm{Na}$ medida em que é assumida em sua totalidade, a vida mesma se revela uma "tentação" ou uma provação - compreendida em sentido ontológico-existenciário -, à qual é impossível subtrair-se da vida em sua plena facticidade. É com base neste horizonte que se norteará a leitura de Heidegger, sem deixar de explicitar a ambiguidade das opçóes do próprio Agostinho em relação às abordagens objetivante e existencial das Confissóes. Nos capítulos 28-29 do livro X das Confissóes (= ao comentário no $\$ 12$ do curso de Heidegger) (HEIDEGGER, 1995, p. 205-210), Agostinho evoca desse modo a miséria da vida humana: esta não seria senão uma "perpétua tentação", uma "tentação sem intervalo" (tempatio sine ullo interstitio), um "peso" (moles, Gewicht), um "fardo" (onus, Last) e, por essa razão, ele se entrega à graça de Deus, junto do qual encontra força e apoio. Na terminologia de Heidegger, a existência humana consiste na "preocupação da vida" (Bekümmerung um Leben), na cura (Sorge). Aos olhos de Heidegger, o curare (das Bekümmertsein, o estar-preocupado) se torna um existenciário (Existenzial), isto é, um modo fundamental de ser da vida fática ou do Dasein (HEIDEGGER, 1995, p. 205s.271; cf. Sein und Zeit, \$\$ 39-42). Neste sentido, os temas agostinianos da dispersão (Zerstreuung) e da ambivalência (Zwiespältigkeit) da vida, que afetam o curare, são interpretados por Heidegger como traços constitutivos da facticidade como tal. Assim, antes de examinar as três direçôes da possibilidade 
da defluxio com o fenômeno da tentação, Heidegger trata da historicidade inerente à vida fática com base nos elementos constitutivos da cura.

\section{A) A dispersão (Zerstreung) CONSTitutiva da Vida fática}

Em conformidade coma experiência de Agostinho, a vida do homem sobre a terra não é, como se diz, uma parte de prazer ou um simples passeio (Sapziergang), mas uma verdadeira miséria (Erbärmlichkeit) e uma verdadeira "provação", marcada, de um lado, pelo fenômeno da "dispersão no múltiplo" (defluxio in multum) e, de outro lado, pelo ordenar (iubere) do movimento inverso de "recolhimento e de retorno à unidade" através da "continência" (continentia) (HEIDEGGER, 1995, p. 205.270). Heidegger compreende as expressóes agostinianas "in multa defluximus" e "in unum per continentiam colligimur et redigimur” em sentido existencial: o multum designa a dispersão constitutiva da vida fática, ou seja, a multiplicidade das significatividades que caracterizam a vida no mundo (das Mannigfaltige): "A vida mundana na multiplicidade de suas significatividades - é assim que é preciso compreender o multum - nos interpela." (HEIDEGGER, 1995, p. 206). O unum indica assim o movimento existencial contrário, o do "autêntico", isto é, a (verdadeira) vida unificada por força da "continência, que não deve ser compreendida no sentido restritivo/moral de abstinência, mas no sentido positivo e dinâmico do esforço de "manter-junto" (zuzammen-halten) os elementos dispersos da vida fática em sua atuação concreta (HEIDEGGER, 1995, p. 205). Trata-se, portanto, de um “'manter-junto' do eu, que é um 'arrancar-se' (zurückreissen) originário da dispersão" (ESPOSITO, 2010, p. 34). Este esforço para a continência consiste no plano da atuação que implica suportar as moléstias e as dificuldades da vida. Esta preocupaçáo de si não possui um fim em si mesmo, mas é a delectatio mesma que é visada na preocupação pela vida: "Finis curae delectatio est." (HEIDEGGER, 1995, p. 208.270).

Deparamos aqui com um dos textos em que Agostinho tematiza a noção de cura com o sentido não somente de tribulação (Bekümmerung) no sentido paulino, mas também, a partir da etimologia latina, de quaero, ou seja, enquanto procura questionadora e ansiosa. É assim que Heidegger, ao privilegiar a passagem citada sobre o comentário aos Salmos de Agostinho, associará estreitamente Sorge e Fraglichkeit em seu caminho posterior de pensamento (GREISCH, 2000, p. 234). Uma vez que Heidegger desvinculou o "prazer", ou delectatio, de sua realização intuitiva em sua interpretaçáo fenomenológica das Confissóes X, 30-39, compreende-se assim o que comenta com justeza Ryan D. Coyne: "[Heidegger] deseja mostrar que a forma 
autenticamente agostiniana da delectatio (uma espécie de deixar-ser) provém do ato que consiste em deixar a objetividade de Deus cair no esquecimento [...] [Após extrair o enunciado desta Exposição sobre o Salmo 7,9] Heidegger religa este esquecimento ao invisível 'fim do cuidado' ou finis curae." (COYNE, 2011, p. 203).

\section{в) A AMbivalêNCIA ( $Z$ WIESPÄLTIGKEIT) CONSTITUTIVA DA VIDA FÁTICA}

É justamente no âmbito da "dinâmica" e da "ambivalência" que deparamos com a historicidade intrínseca da existência fática para Heidegger. Tais elementos ("dinâmica" e "ambivalência") constituem a vida como cuidado: "Nas circunstâncias adversas, lamento o bem-estar, no tempo do bem-estar, temo as adversidades." (AGOSTINHO, Conf. X,28,39). Ora, o fardo da vida é igualmente evidente através de sua ambivalência ou conflitualidade fundamental (Zwiespältigkeit): Agostinho constata que a vida sobre a terra está dividida entre tristeza e alegria, temor e desejo, adversidade e prosperidade: "O si está implicado em um experimentar histórico - ainda que frequentemente o seja somente 'em uma medida fraca'. O motivo fundamental: o histórico contido na cura mesma." (HEIDEGGER, 1995, p. 208). O dilaceramento entre essas situaçôes extremas é um traço constitutivo da vida fática que Heidegger definirá aqui como "ambivalência: "Chamamos 'ambivalência' esta co-presença particular dos diferentes sentidos referenciais do cuidado no seio da experiência fática da vida [...] Essas experiências mesmas do cuidado não estão simples aí, por assim dizer, em um fluxo psíquico, mas as possuímos elas mesmas no experimentar [Erfahren] - (este fato de tê-las, é seu 'ser')." (HEIDEGGER, 1995, p. 208). Posteriormente Heidegger aprofundará esse fenômeno através do existenciário (Existenzial) da ambigüidade (Zweideutigkeit) no $\$ 37$ de Sein und Zeit (HEIDEGGER, 2012, p. 173-175/487-492). Em outras palavras: no contexto histórico-fático da vida, a preocupaçáo se realiza seguindo um sentido referencial dinâmico: as múltiplas significatividades, nas quais o homem vive, são ora prospera (favoráveis, úteis, sãs, desejadas, atraentes), ora adversa (hostis, desagradáveis, temidas, opostas ao que se aspira).

Assim, o homem é dividido, primeiramente, entre o desiderare e o timere, divisão donde decorrem todas as outras experiências ambivalentes do cuidado. Esta divisão é experienciada como uma dilaceração dramática, que aparecerá amplamente no fenômeno da tentação. A presença simultânea desses referenciais que se modificam constantemente não se reduz a uma 
simples constatação que consiste em uma tomada de conhecimento teórico, mas essas experiências do cuidado são elas mesmas a atuação da experiência de mim (do eu mesmo) (HEIDEGGER, 1995, p. 208-209). O dilaceramento é de tal modo que na atuação (histórica) dessas experiências não se vive somente na insegurança permanente (Unruhe) e na incerteza absoluta (nescio), mas também se tem o perigo real de ceder à moda e resvalar na direção do inautêntico. Daí a qualificação de Heidegger de um "dilaceramento diabólico" (HEIDEGGER, 1995, p. 209) que se revela no experienciar a mim mesmo. É um conflito vital, dinâmico e dilacerante. Agostinho vê este dilaceramento como uma "ferida", que não pode ser curada com suas próprias forças e nem vencida com os esforços humanos, mas somente com a ajuda e a misericórdia de Deus: "Agostinho declara que já é uma coisa preciosa compreender que a continentia, que repousa simplesmente em nossa própria força, é desesperante, e que se devemos 'tê-la' [gehabt] de um modo ou de outro, é preciso que ela nos seja dada." (HEIDEGGER, 1995, p. 209).

Nesta apropriação fenomenológica de Heidegger, a tensão dramática entre o eu e Deus se 'resolve' na irredutibilidade do "como" (Wie) em relação ao "que coisa" (Was): deixa-se completamente de lado o conteúdo da experiência: a novidade do encontro histórico do eu com Deus através de Cristo (novidade "contaminada" por uma concepção "espiritual", mas abstrata do Logos divino). Deste ponto de vista, a historicidade é, portanto, compreendida como autoreferência, e a preocupação inquieta de si em busca de sentido é traduzida em termos de uma "motilidade" que tem seu paradigma ontológico no conceito aristotélico de physis: o ente que tem em si mesmo o princípio do movimento.

No diálogo ideal instaurado por Heidegger entre Agostinho e Aristóteles acerca do tema da facticidade do viver, segundo a tese da "inversão cronológica" de Costantino Esposito, do primeiro ele herdou a ideia do compreender como mobilidade de atuaçáo peculiar da vida, descortinada na inquietude de sua perene busca de sentido e, do segundo, a presença de um estreito nexo existente entre o compreender e o ter: no quadro das análises heideggerianas relativas ao "movimento" (Bewegtheit), se trata de uma interrogação acerca da compreensibilidade da vida em relação a si mesma, na forma de um enigma radical do poder "ter-a-si", isto é, do recolher-se e do "manter-se-junto" do viver, na forma de um "arrancando para trás" do dispersar-se na multiplicidade. Se aqui é comum a ideia de uma unidade rompida pela dispersão, o modo de retornar à posse de tal unidade parece depender, ora - no caso de Agostinho 
-, do exterior, no sentido de que nem tudo pode ser decidido exclusivamente pelas forças do homem, ora - no caso de Heidegger -, do interno do próprio viver, como sua possibilidade mais própria.

É com base nesta autonomia cinética do viver em relação à própria realização que reside a herança aristotélica, na medida em que dá voz categorialmente - à possibilidade "endógena" do viver de recolher-se na unidade de uma forma determinada. Em outras palavras: para Heidegger, o encontro com Agostinho pode realizar-se só mediante uma "re-tradução" do fenômeno do viver, realizada através das categorias aristotélicas: "Porque somente Aristóteles pode e deve salvar, paradoxalmente, a descoberta que, depois dele, Agostinho foi o primeiro a fazer." (ESPOSITO, 2010, p. 23). É justamente eliminando o neoplatonismo, enquanto presença de um apoio extrínseco em relação à vida mesma, e, colocando também fora de circuito a validade daquela relação homem-Deus, experienciada em toda sua dramaticidade e descortinada por Agostinho nas Confissóes, que, segundo Heidegger, se chega então a compreender que só assim o viver, no como de seu estar-em-movimento, pode aparecer, na plenitude de seu fluxo, em toda a sua autonomia e irredutibilidade substancial. Como bem asseverou Costantino Esposito a propósito do jogo heideggeriano,

e assim a relação dramática com a origem - o que para Agostinho significa essencialmente 'viver' na descoberta do 'tu' - se inverte na impossibilidade da origem como sentido único da vida do ser-aí: o ente que se 'move' a partir de si mesmo [...] Nâo somente o "tu", mas também o "eu" voltam a ser impossíveis, e não a despeito da experiência de Agostinho, mas por causa desta - eis a aporia sem solução por parte de Heidegger. (ESPOSITO, 2010, p. 46.42).

\section{B. As três POSSIBILIDAdes da TENTAÇÃo NO MUNDo COMO DIFERENTES MOVIMENTOS DE “DISPERSÁO”}

A parte crucial do curso do semestre de verão de 1921 diz respeito às Confissóes X, 30-39, passagem na qual Agostinho considera a tentação, e a análise heideggeriana fornecerá as referências gerais para enquadrar a especificidade da facticidade agostiniana. Portanto, nos $\$ \$ 13,14$ e 15 de sua preleçáo Agostinho e o neoplatonismo, Heidegger interpreta as três possibilidades da tentação no mundo (concupiscentia carnis, concupiscentia oculorum, ambitio saeculi) como diferentes movimentos de "dispersão" em conflito com o contramovimento 
da "continência" com base no seguinte texto de Confissóes X, 29, 40: "Tu nos ordenas a continência [...]. Sim, a continência nos recolhe e nos conduz à unidade que tínhamos perdido dissipando-nos no múltiplo." (ver sobretudo BRITO MARTINS, 1998, p. 320-330; DAHLSTROM, 2010). Este trecho é assim reformulado por Heidegger (1995, p. 205): "Pois in multa defluximus, nos dispersamos no múltiplo e nos dissolvemos na dispersão [Zerstreutheit]. Tu ordenas o movimento contrário [Gegenbewegung] que se opóe à dispersão, à dissolução [Auseinanderfallen] da vida." Esta condiçáo humana, enquanto concupiscência da carne, concupiscência dos olhos e ambição do século, é interpretada fenomenologicamente em três direçóes fundamentais da dispersão (defluxus) da vida fática. São, portanto, três formas de "perigo" para a existência (HEIDEGGER, 1995, p. 211) que apontam para a incerteza e a instabilidade totais da vida concreta, ou seja, de uma existência em mobilidade ontológica na qual nunca o viver poderia significar simplesmente o ser que se é, e só isso, como se o existir pudesse ser objetivado em dado "real". Portanto, o exame desta experiência não possui uma conotação moral, nem tampouco intenção psicológica, mas tem um alcance ontológico: na verdade a exposição de Agostinho retira sua unidade " $\mathrm{da}$ atitude fundamental da confessio, isto é, ele confessa como tentaçóes dela procedem e aí se produzem e como se comporta (ou tenta comportar-se) em relação a ela" (HEIDEGGER, 1995, p. 212). Este alcance ontológico pode ser descortinado com base na "definição" heideggeriana do confiteri: é uma Haltung, ou melhor, uma Grundhaltung (HEIDEGGER, 1995, p. 177-178.283): se trata de uma disposição de ser, de uma atitude fundamental na qual nos mantemos, etc. (ARDOVINO, 2016, p. 226). A subdivisão das diversas formas de tentação parte do texto bíblico de 1 Jo 2,15-17:

Não ameis o mundo, nem as coisas do mundo. Se alguém ama o mundo, não está nele ao amor do Pai; pois tudo o que está no mundo é concupiscência da carne, concupiscência dos olhos e soberba da vida, coisas que não procedem do Pai, mas do mundo.

\section{A) A CONCUPISCÊNCIA DA CARNE}

Ao confessar sua primeira tentação, Heidegger enfatiza que Agostinho o faz, portanto, não com base "em uma atitude biológico-psicológico-teorética, mas em função dos caracteres nos quais ele a experimentou faticamente e continua a experimentá-la, isto é, como e quando isso se produz: malitiae diei et noctis (a cotidianidade)" (HEIDEGGER, 1995, p. 212). As três formas 
de dispersão constituem para Heidegger a dimensão de incerteza própria da vida. Agostinho não pode estar seguro de si mesmo e, uma vez que está continuamente submetido às incertezas da vida, caminha às cegas na escuridão. Agostinho não possui jamais a possibilidade de "invocar um momento que seja por assim dizer fixo" durante o qual ele possa penetrar a si mesmo. Justamente porque a experiência da posse de si mesmo (mich selbst haben) se realiza, na tendência e na direção desta vida, em um "vai-e-vem". Como ele mesmo assevera: "Ninguém deve se sentir seguro nesta vida - que toda ela é chamada uma tentação - se aquele que pôde de pior tornar-se melhor, de melhor não se tornará pior.” (HEIDEGGER, 1995, p. 217). É nesta incerteza de vida como caminho inquieto que se instaura a tentação enquanto tendência de transformar a incerteza em comodidade ("um atitude in carne... colocada a serviço da maior comodidade"), que se insinua no movimento em direção ao caráter "autêntico", existencialmente decisivo: na "voluptas oculorum" de minha carne, por exemplo, o ver não diz respeito a puros objetos sensíveis, mas está referido a um "como [Wie] do ter comércio com [Umgehensmit], (in carne)", onde o que é experienciado possui um caráter de significatividade particular (HEIDEGGER, 1995, p. 218). Esta tentação "in carne” identificada por Heidegger consiste em uma absolutização do horizonte significativo mundano que basta a si mesmo tornando-se fonte primária de sentido; se trata de um entreter-se na carne mesma na medida em que o homem, contentando-se com ele mesmo e com sua progressão nas significatividades experienciadas como mundo, assume o papel da doação do sentido para a facticidade. Daí deriva uma espécie de inversão na ordem hierárquica das motivaçôes, um "deixar-se deslizar no cálculo das significatividades". Neste cálculo, se prioriza o horizonte mundano e não mais o divino, negligenciando certas possiblidades a favor "de instalar-se no real' (HEIDEGGER, 1995, p. 218-219). A perda da referência a Deus é evidente, especialmente na forma da concupiscência da carne, onde os homens se deixam atrair pelas belezas exteriores perdendo a orientação em direção à verdadeira luz:

A segurança e a vivacidade da atuação da cura e do empenho, eles náo as reservam a si mesmos e à sua relação interior a Vós. Ao contrário, as dissipam e as dispensam com ligeireza nos relaxamentos deleitáveis e nas preguiças onde se comprazem. Náo as possuem mais à disposição por uma decisáo autêntica. Fracassam, embora aos olhos do mundo dos outros eles se dêem uma importância artificiosa e assumam uma postura falsa como gozadores e conhecedores dessas coisas, comportando-se como se tivessem uma confiança e familiaridade particulares com o sentido mundo e dos mistérios da vida. (HEIDEGGER, 1995, p. 221). 


\section{B) A CONCUPISCÊNCIA dos OlHOS: AS TENTAÇÓES DA CURIOSIDADE}

Diferentemente da concupiscência da carne caracterizada por uma tendência de imersão na carne mesma, a concupiscentia oculorum concerne ao desejo do "inspecionar o entorno [Sich-umsehen] [e não do ter-comérciocom, Umgehenmit] nos domínios e nos campos mais diversos" da experiência (HEIDEGGER, 1995, p. 223). A forma mais conhecida de concupiscência dos olhos é a curiosidade, "a sede do novo, a curiosidade vã, que se traveste sob o nome de conhecimento e de ciência". Na terminologia de Heidegger, se trata de um "inspecionar curioso no mundo" apresentando-se como uma verdadeira e própria concupiscência da cura, da vã ocupação com o mundo: "O simples fato querer-ver, a pura curiosidade, é o sentido dominante e precisamente quando a experiência se realiza com uma carga emocional: medo, pavor, arrepio.” (HEIDEGGER, 1995, p. 224). Nisso reside a diferença com a primeira forma de tentação compreendida como "deleitar-se na carne": na concupiscência dos olhos, o sujeito é ativo, toma iniciativa, explora experimenta "per carnem". Em ambos os casos, deparamos com o cuidado (cura) em vista de usufruir. Com a expressão per carnem, se indica o sentido referencial, isto é, o acesso no apetite de ver, conhecer e experimentar o que é carnal, sensível, ou seja, tudo o que passa pelos sentidos. Sem desconhecer que Agostinho mostra a riqueza semântica do ver em Conf. X, 35, 54 , Heidegger reitera em sua análise a distância entre o estatuto fático desta experiência e o da tomada do ato cognoscitivo: o sentido referencial específico do ato de ver não é o do experienciar fático da vida: o "ver" in officio vindenti ou cognoscendi implica “deixar alguma coisa tornar-se expressamente 'objeto' (Gegenstand) da simples tomada de conhecimento [...], é o experimentar que toma conhecimento e que dá a conhecer na sensibilidade em geral: o 'ver'”5.

\footnotetext{
4 "Usamos também a palavra 'ver' para os outros sentidos quando os aplicamos ao ato de conhecer. $\mathrm{Na}$ verdade, não dizemos: ouve o que brilha, ou: cheira como resplandece, ou: saboreia como reluz, ou: apalpa como cintila, pois se diz que todas estas coisas são vistas. No entanto, não só dizemos: vê o que brilha, porque só os olhos o podem sentir, mas também: vê o que soa, vê o que cheira, vê o que tem sabor, vê como é duro. Por isso, a experiência geral dos sentidos é chamada, como foi dito, concupiscência dos olhos, porque os restantes sentidos, quando procuram conhecer algum objeto, também usurpam para si, por analogia, a função de ver, na qual os olhos têm a primazia."

${ }^{5}$ Heidegger (1995, p. 226). Portanto, com base nesta descrição de Agostinho, Heidegger reiterará posteriormente em Sein und Zeit ( $\$ 36$. Die Neugier) que esta "curiosidade" não se preocupa em ver para compreender o que se vê (isto é, "ser para" isto), mas somente em ver: neste somente ver se livra o si-mesmo do ser-junto (Seinbei) ao ente que se encontra no mundo, e que é pré-compreendido como utilizável: "O Dasein se deixa empolgar unicamente pelo aspecto do mundo, um modo-de-ser em que ele se empenha em livrar-se de si mesmo como ser-no-mundo, livrando-se de ser junto ao próximo
} 
A curiosidade não é perigosa, primeiramente, em relação ao conteúdo, mas por causa sobretudo do tipo de referência e da relação que esta instaura com aquilo que está em nosso entorno: nela o sentido referencial como tal é obstinado no sentido de que se atribui prioridade absoluta ao ver ["ver quer dizer dar-se previamente [vorgeben] um objeto como objeto"] que determina todas as experiências fáticas de modo decisivo e último ${ }^{6}$ : por exemplo, na religião "Deus é colocado à prova quando lhe pedimos sinais e prodígios, que não são desejados com um objetivo salutar, mas simplesmente para dele ter experiência". Nesse sentido, Deus se torna até mesmo um "fator do experimentar humano" (HEIDEGGER, 1995, p. 224-225). É comentando esta forma de tentação que aparece pela primeira vez o termo Verfallen: "Nesta curiosidade [na acentuação determinada de uma possibilidade de experiência e na determinada atuação desta], reside também o decair [das Verfallen]." (HEIDEGGER, 1995, p. 224). Ao nível da leitura genealógica do pensamento de Heidegger, deparamos aqui com eventuais paralelos que dizem respeito à espécie de nascimento necessário da facticidade e do existenciário-ontológico Verfallenheit $(q u e d a)^{7}$ : por exemplo, a direção das possibilidades da tentação em cada caso está também "aî" $(d a)$ na facticidade do Dasein (DAHLSTROM, 2010, p. 280). Em relação à segunda tentação, Heidegger considera, por fim, esta "vana cura" como caminho maior e ocasião "sempre presente" da dispersão da vida fática: "As ingerências da curiosidade impregnam as experiências fáticas.” (HEIDEGGER, 1995, p. 227).

utilizável cotidiano. Mas, ao ficar em liberdade, a curiosidade não se ocupa em ver para entender o visto, isto é, para entrar numa relação de ser com o visto [in ein Sein zu ihm zu kommen], mas busca somente vê-lo." (HEIDEGGER, 2012, p. 173/485).

6 "O sentido de referência como tal é obstinadamente radicado, bem como obstinado e prioritário é o sentido integral do ver é, que determina todo experienciar fático de modo decisivo e último." (HEIDEGGER, 1995, p. 226).

7 A importância desse fenômeno está na base das consideraçóes fenomenológicas de Heidegger sobre a determinação existenciária do decair (das Verfallen) do Dasein: "O Dasein, de pronto e no mais das vezes, é junto [bei] ao 'mundo' da ocupação [...]. O ser do decair [Die Verfallenheit] no 'mundo' significa ser-absorvido [Aufgehen] no ser-um-com-outro, na medida em que este é conduzido por falatório, curiosidade e ambiguidade." (HEIDEGGER, 2012, p. 175-176/493-495). Portanto, a descrição da estrutura existenciária do Verfallen implica a noção da Versuchung, ou seja, do caráter "tentador" do "ser-no-mundo". O Dasein se tornou "para si-mesmo uma tentação", subtendendo o seguinte: a tentação não vem de fora, mas do interior. Mesmo na ausência de todo tentador, o Dasein, existindo faticamente, será sempre tentado. 


\section{C) A AMBIÇÁ̃o do SÉCULO}

Enquanto as duas primeiras tentaçóes concernem principalmente às relaçôes do sujeito com o mundo compartilhado e circundante (Umgehen-mit e Sich-umsehen-in), não obstante suas diferenças essenciais, a terceira forma de tentação (ambitio saeculi) é a única que se interessa pelo amor-próprio como tal no sentido preciso de expressar mais concretamente a relaçáo de si e a si mesmo, ou seja, o mundo do si-mesmo (HEIDEGGER, 1995, p. 227-228). Trata-se aqui simplesmente de uma preponderância na medida em que o Selbswelt é, em seu orgulho, em sua sede de elogio ou em sua vontade de ser valorizado, o fim mesmo de tal experiência. Esta prioridade já é preparada com o movimento das Confissóes X, 30-39 na direção de um autêntico "ter-a-si-mesmo" (Sich-selbsthaben). Assistimos ao converter-se da alma ad proprium bonum. Em termos fenomenológicos isso significa que a "significatividade própria se torna fins delectationis" no sentido da validade do si na experiência fática, ou seja, nas coesóes da vida ora do mundo circundante ora, por fim, do mundo do si-mesmo (HEIDEGGER, 1995, p. 228). Em sentido geral, a ambição mundana consiste em "desejar ser temido e amado pelos homens" (AGOSTINHO, Conf. X, 36). A direção das possibilidades de ser tentado diz respeito ao mundo circundante e a esta tentação, "onde se trata do amar e do temer, ou do ser amado e do ser temido, está sempre 'aí' na facticidade do ser-aî” (HEIDEGGER, 1995, p. 230: "eine necessitas").

A divisão dessa ambição mundana acontece de duas maneiras: de um lado, o primeiro tipo de ambição mundana é "o amor do louvor" (amor laudis) que concerne à relação entre a alma e seu "universo comunitário". De outro lado, o segundo tipo provém da "excelência privada" (excellentia privata) ou da "autocomplacência” (sibi placens), traduzido por Heidegger como "atribuir importância a si mesmo". Então deparamos com a divisão entre o desejo de "valorizar a si mesmo" (Sich-in-Geltung-setzen) e o cuidado de "atribuir importância a si mesmo" (Sich-selbst-wichtignehmen). Portanto, a valorização de si mesmo (Selbstgeltung) se funda na consideração própria de si (Selbstwichtignahme), a qual se apresenta como uma forma particular da cura ou Selbstbekümmerung (cuidado de si) (HEIDEGGER, 1995, p. 227-228).

Direcionando-se para segunda forma de ambição mundana, Heidegger aponta um indício da certeza de si verdadeiro. Uma perversão sutil se insinua aqui: a autocomplacência. $\mathrm{O}$ amor pelo louvor a si mesmo conduz o sujeito não 
somente a desejar ser valorizado, mas também a reivindicá-lo como tal diante de si mesmo e diante dos outros, ou seja, ele atribui importância a si mesmo no Mitwelt e diante de si mesmo. A tentação desvia o sujeito da autêntica direção do placere: em vez do amor supremo (amor maximus) ou do temor piedoso (timo castus) de Deus, a quem o homem deve toda boa obra e louvor, considerando tudo como donum Dei, o comprazer-se consigo mesmo (sibi placens) visa, ao contrário, ao mundo do si-mesmo (Selbstwelt) que é tomado a sério na atuação da experiência fática da vida. É assim que Heidegger, comentando a força e natureza do amor próprio em Confissóes X, 39 na direção do Selbstwelt, distingue quatro modos do gaudere perante si mesmo:

Se comprazem em si mesmos, mas desagradam muito [a Deus]: (1) náo porque se decepcionaram das coisas que não são boas coisas como se fossem boas, mas (2) porque se gloriam das boas coisas como se fossem os seus [bens]; (3) ou até se eles se regojizam como teus, eles os atribuíram aos seus próprios méritos; (4) ou mesmo como se fossem obtidos pela tua graça, todavia não se alegrando socialmente, mas negam tua graça aos outros. (HEIDEGGER, 1995, p. 238-240; cf. Conf. X, 39).

O dilema de atribuir importância a si mesmo é associado aqui ao problema da autorepresentaçáo (COYNE, 2011, p. 204-205). De um lado, ao reivindicar diante do mundo circundante o ser importante em si mesmo e diante de si mesmo, o sujeito depara com a seguinte consequência: a tentação mundana implica o fracasso de reconhecer que a alma nada é diante de Deus. De outro lado, superar esta tentaçáo através da continentia e da iustitia conduz esta mesma alma na direção de colocar-se diante dela mesma como nihil. Acontece, porém, que esta tentação faz com que a alma se coloque diante dela mesma como "alguma coisa" de importante. Ser "algo" de importante se dá sempre quando justamente o ser-aí se encontra neste tipo de posse de si mesmo (Sich selbst haben) na plena facticidade (HEIDEGGER, 1995, p. 241). O movimento contrário indicado por Agostinho para superar o caráter "angustiante" dessa tentação mundana (continentia e iustitia) implica no impedimento do mundo do si-mesmo "dispersar-se" nas tendências decadentes do mundo circundante. Mas, diante desta tentaçáo do "tomar a si mesmo como importante", a alma paralisa não somente sua procura pelo divino, mas também relativiza a graça divina na medida em que, a alma criada, tão profundamente atolada no pecado, neste autoapresentar-se ela se transforma em ídolo. 
Nesses quatro modos de tomar-se como importante diante de si-mesmo, o peculiar é que uma autêntica apreciação do bonum é certamente 'mais' realizada [...] mais igualmente que o si se vê cada vez a si mesmo de um modo novo, antepóe seu mundo próprio pessoal, atribuindo-lhe ainda uma importância decisiva, mesmo se unicamente enquanto é este mundo aquele em e diante do qual se realiza a graça e o bonum. Mas isso quer dizer que precisamente no modo em que o si-mesmo já náo se atribui mais nada como sendo seu próprio desempenho, tudo é abandonado a favor do alegrar-se diante de Deus. (HEIDEGGER, 1995, p. 240).

Eis que deparamos aqui com a explicação da tentação e o meio para precaver-se dela. Há, primeira, dois caminhos através dos quais a alma se dobra sobre sua própria objetivação: de um lado, a alma sente prazer de reconhecer a si mesma como receptora da graça; neste caso, o dom de Deus é anulado pelo simples reconhecimento desta evidência; de outro lado, a alma anula sua própria representaçáo do bem reconhecendo esta representaçáo como tal. Daí surge a pressuposição evidenciada por Heidegger: a alma não pode se reconhecer sem idolatrar-se, nem reconhecer a graça sem desejá-la. Com base nesses movimentos escondidos, Heidegger conclui: "Tudo se anula [...] e tudo é invalidado em razão do summum bonum." (HEIDEGGER, 1995, p. 240). As condiçôes do regozijar-se verdadeiro na presença de Deus emergem: elas voltam a ser desprovidas de toda autoapresentação como tal. Uma vez imersa na apropriação de sua significação religiosa louvando o divino, a alma recusa ipso facto inserir-se em qualquer significação mundana. Acontece, porém, com base nesta atitude, a alma deve anular essencialmente cada um dos "modos de tomar-se como importante diante de si-mesm[a]". A alma assim se torna "absoluta" e se remete à sua própria destituição como um nihil (ein Nichts) diante de Deus (HEIDEGGER, 1995, p. 235).

Nesse caso, considerando a apropriação fenomenológica das Confissóes, o quaerere Deum de Agostinho conduziria a uma forma de a-teísmo: "O ato de confissão deve culminar no desvelamento da negação de si como condição de acesso a Deus, ao passo que esta negaçáo sutiliza simultaneamente à alma as condiçôes de sua experiência do divino." (COYNE, 2011, p. 206). Portanto, em vez da dinâmica agostiniana que consiste no repouso em Deus, considerado aqui em sua objetividade metafísica enquanto fruitio Dei, Heidegger aponta para uma "preocupação [Bekümmerung] mais pura, decisiva e última do si-mesmo” (HEIDEGGER, 1995, p. 240). Só quando a alma reconhece que, por sua própria iniciativa, náo pode permitir a Deus 
que seja Deus, entấo se abre a possibilidade de regozijar-se autenticamente em Deus. É exatamente aí que a alma consegue ultrapassar seu desejo de ser louvada existindo como se ela nada fosse, sendo desprovida de sentido: "O ab esse [o fato de estar ausente] do laus [louvor] pode unicamente realizar-se [...] expondo-se à desgraça e ao menosprezo." (HEIDEGGER, 1995, p. 267). Enquanto se encontra nadificada ao nível do representativo, isto é, como "ausência a si-mesma", a alma acessa de maneira paradoxal a uma afecção do si que equivale a uma autêntica posse de si-mesmo oposta, ontologicamente, ao sibi placens: o ato de confessar a Deus reduz a alma ao nada de tal modo que seu comportamento de nibil o afeta. Esta afecçáo de si abre a alma à invisibilidade de sua finis curae, que se exibe como um nada diante de Deus e, deste modo, se apaga toda certeza epistemológica do si. Este nibil, originando-se da dinâmica na criação divina, expressa fenomenologicamente para Heidegger o enigma e a estranheza do nada que alma possui como seu próprio esse (COYNE, 2011, p. 207). O regozijar-se verdadeiro, ou a oferenda a Deus de tudo o que se possui, náo liberta a alma da inquietude, mas a intensifica com produção da ansiedade na posse do si (na plena facticidade) (HEIDEGGER, 1995, p. 241).

Por fim, nesse percurso sobre a fenomenologia do livro X das Confissóes com base na noçáo de tentatio, vimos que para Heidegger "aquilo de que se fala" na prática da confessio de si-mesmo, nunca é a explicitação autêntica da confessio (HEIDEGGER, 1995, p. 318). Na verdade primordial é o "como" se vive o ser tentado enquanto existência que "acontece" sem nunca se realizar e o "diante de" quem: a vida é, portanto, uma "tentação sem intervalo", um fenômeno que se dá como mobilidade ontológico-existencial. Nas Confissóes de Agostinho, Heidegger descobriu desse modo significados originários do ser da vida: a facticidade ("o ser como ter"), o "ser histórico" ("o ser como acontecer") e a "preocupação" ("o ser como procurar") da vida (ESPOSITO, 2010, p. 23).

SANTOS, B. S. Heidegger and Augustine: the phenomenon of the tentatio and the historicity of the self (Selbst) in the phenomenological appropriation of Book X of the Confessions. Trans/Form/Ação, Marília, v. 42, p. 135-158, 2019. Edição Especial. 
ABstract: The article deals with the phenomena of healing, according to the phenomenological appropriation of Book X of Augustine's Confessions made by Martin Heidegger in the course at Freiburg entitled Augustinus und der Neuplatonismus (SS1921). I intend to present the phenomenon of temptation and the historicity of the self. According to the genuine appropriation of the being of the life of Augustine, the "tentatio" (Versuchung) becomes an expression of the mobility of the historical-actuative existence, which can never be understood as "stillness". It is the life itself which, assumed in its totality, represents a "temptation", an ordeal - understood in an ontological-existential sense - insofar as it indicates the "how" (Wie) of facticity. In the search for this originating "how", there arises the fundamental question of what life is for itself: quaestio mihi factus sum (I made of myself a question). We see, in the loss of "I am", the process of temporalization as deformitas, as the defluxus in distraction, as the fall into the "inauthentic". On the basis of this appropriation of the being of Augustine's life, we will reach the core of the phenomenon of healing, understanding healing as the fundamental character of phatic life and recognizing in the search for God the constitution of facticity and self-healing expressed in this search.

KeYwords: Healing. Life. Phenomenology. Original Christianity. Facticity.

\section{REFERÊNCIAS}

ARDOVINO, A. Heidegger: esistenza ed effettività. Dall'ermeneutica dell'effettività all'analitica esistenziale (1919-1929). Milano: Guerini e Associati, 1998.

ARDOVINO, A. Interpretazioni fenomenologiche del cristianesimo. Vaticano: Lateran University Press, 2016.

ARRIEN, S.-J.; CAMILLERI, S. (éd.). Le jeune Heidegger 1909-1926. Paris: J. Vrin, 2011.

ARRIEN, S.-J. 14. L'inquiétude de la pensée: l'herméneutique de la vie du jeune Heidegger (1919-1923). Paris: PUF, 2014.

BARASH, J. A. Heidegger e o seu século: tempo do ser, tempo de história. Lisboa: Instituto Piaget, 1997.

BARASH, J. A. Theology and the historicity of faith in the perspective of the Young Martin Heidegger. In: McGRATH, S. J.: WIERCINSKI, A. (ed.). A Companion to Heidegger's Phenomenology of Religious Life. Amsterdam; New York: Rodopi, 2010. p. 93-113.

BRITO MARTINS, M. M. L'herméneutique originaire d'Augustin en relation avec une ré-appropriation heideggerienne. Mediaevalia: Textos e Estudos, Porto: Fundação Eng. António de Almeida, v. 13/14, 1998.

CAMILLERI, S. Phénoménologie de la religion et herméneutique théologique dans la pensée du jeune Heidegger. Dordrecht: Springer, 2008.

CAMILLERI, S. Heidegger et les grandes lignes d'une phénoménologie herméneutique du christianisme primitif. Dordrecht: Springer, 2017. 
CARBONE, G. La questione del mundo nei primi corsi friburghesi di Martin Heidegger. Milano: Mimesis Edizioni, 2017.

CROWE, B. D. Heidegger's religious origins. Destruction and authenticity. Indiana: Indiana University Press, 2006.

CROWE, B. D. Heidegger's phenomenology of religion: realism and cultural criticism. Bloomington/Indianapolis: Indiana University Press, 2008.

COYNE, R. D. Herméneutique et confession: ce que le jeune Heidegger a trouvé chez Augustin. In: ARRIEN, S.-J.; CAMILLERI, S. (éd.). Le jeune Heidegger 1909-1926, 2011. p. $185-211$.

DAHLSTROM. D. Truth and tentation: confessions and existential analysis. In: McGRATH, S. J.; WIERCINSKI, A. (ed.). A Companion to Heidegger's Phenomenology of Religious Life. Amsterdam; New York: Rodopi, 2010. p. 263-284.

GREISCH, J. L’Arbre de vie et l'Arbre du savoir: les racines phénoménologiques de l'herméneutique heideggerienne (1919-1923). Paris: Cerf, 2000.

ESPOSITO, C. Heidegger: de Agostinho a Aristóteles. Kriterion, v. 51, n. 121, p. 21-46. jun., 2010.

HEIDEGGER, M. Die Idee der Philosophie und das Weltanschauungsproblem (Kriegsnotsemester1919). In: HEIDEGGER, M. Zur Bestimmung der Philosophie. (GA 56/57) Frankfurt am Main: Vittorio Klostermann, 1999. p. 1-117.

HEIDEGGER, M. Grundprobleme der Phänomenologie [Wintersemester 1919/20] (GA 58). Frankfurt am Main: Vittorio Klostermann, 1993, (22010).

HEIDEGGER, M. Phänomenologie dês religiösen Lebens [WS 1920/1921] (GA 60). Frankfurt amMain: Vittorio Klostermann, 1995. (22011).

HEIDEGGER, M. Fenomenologia da vida religiosa. Tradução brasileira de Enio Paulo Giachini, Jairo Ferrandin e Renato Kircher. Petrópolis; Bragança Paulista: Vozes; Editora Universitária São Francisco, 2010. (22014).

HEIDEGGER, M. Phänomenologische Interpretationen zu Aristoteles. Einführung in die phänomenologische Forschung [WS 1921/1922] (GA 61). Frankfurt am Main: Vittorio Klostermann, 1985. ( $\left.{ }^{2} 1994\right)$.

HEIDEGGER, M. Ser e tempo. Edição em alemão e português. Tradução, organização, nota prévia, anexos e notas por Fausto Castilho. São Paulo; Petrópolis: Editora Unicamp; Vozes, 2012.

KISIEL, T. The genesis of Heidegger's "Being and time". Berkeley; Los Angeles; London: University California Press, 1993.

HEIDEGGER, M. Lindication formalle de la facticité: as genèse et as transformation. In: COURTINE, J.-F. (éd.). Heidegger 1919-1929. Paris: J. Vrin, 1996. p. 205-219. 
HEIDEGGER, M. Note for a work on the 'phenomenology of religious life' (19161919). In: McGRATH, S.J.; WIERCINSKI, A. [ed.]. A Companion to Heidegger's Phenomenology of Religious Life. Amsterdam; New York: Rodopi, 2010. p. 309-328.

McGRATH, S. J.; WIERCINSKI, A. (ed.). A Companion to Heidegger's Phenomenology of Religious Life. Amsterdam; New York: Rodopi, 2010.

MBIMBI MBAMBA, J.-C. La phénoménologie de la religion du jeune Heidegger et sa signification pour la théologie. Peter Lang: Frankfurt am Main, 2012.

PERRIN, C. Entendre la métaphisique. Les significations de la pensée de Descartes dans l'oeuvre de Heidegger. Louvain; Paris: Peeters, 2013.

QUESNE, Ph. Les Recherches philosophiques du jeune Heidegger. Dordrecht: Kluwer Academic Publishers, 2003.

RUOPPO, A. P. Vita e metodo nelle prime lezioni friburghesi di Martin Heidegger (19191923). Firenze: Di Marco; Le Cáriti, 2008.

SAVARINO, L. Heidegger e il cristianesimo (1916-1927). Napoli: Liguori Editore, 2001.

SOMMER, C. Heidegger, Aristote, Luther. Paris: PUF, 2005.

SOMMER, C. (Qui) suis-je? Quaestio augustinienne et Seinsfrage heideggerienne (19191927). In: ARRIEN, S.-J.; CAMILLERI, S. (éd.). 2011. Le jeune Heidegger 1909-1926. Paris: J. Vrin, 2011. p. 173-184.

STAGI, P. Der faktische Gott. Selbstwelt und religiöse Erfahrung beim jungen Heidegger. Würzburg: Königshausen; Neumann, 2007.

SURACE, V. L'inquietudine dell'esistenza: le radici luterane dell'ontologia della vita di Martin Heidegger. Milano: Mimesis, 2014.

THOMÄ, D. Die Zeit des Selbst und die Zeitdanach. Zur Kritik der Textgeschichte Martin Heideggers 1910-1976. Frankfurt am Main: Suhrkamp, 1990.

VAN BUREN, J. The Young Heidegger rumor of the hidden King. BloomingtonIndianapolis: Indiana University Press, 1994.

VICARI, D. Ontologia dell'esserci. La riproposione della "questione dell'uomo" nello Heidegger del primo periodofriburghese. Zamorani: Torino, 1996. p. 100-104.

WIERCINSKI, A. Heidegger's atheology: the possibility of unbelief. In: McGRATH, S. J.; WIERCINSKI, A. (ed.) A Companion to Heidegger's Phenomenology of Religious Life. Amsterdam; New York: Rodopi, 2010. p. 149-178.

ZABOROWSKI, H.A. Genuinely religiously orientated pesonality": Martin Heidegger and the religious and theological origins of this philosophy. In: McGRATH, S. J. WIERCINSKI, A. (ed.). A Companion to Heidegger's Phenomenology of Religious Life. Amsterdam; New York: Rodopi, 2010. p. 3-19. 
ZACCAGNINI, M. Christentum des Endlichkeit. Heideggers Vorlesungen: Einleitung in die Phänomenologie der Religion. Münster; Hamburg; London: LIT Verlag, 2003.

ZAHAVI, D. Comment examiner la subjectivité? À propos de la réflexion: Natorp e Hiedegger. In: ARRIEN, S.-J.; CAMILLERI, S. (éd.). 2011.Le jeune Heidegger 19091926. Paris: J. Vrin, 2011. p. 95-118.

ZEAMI, G. La conversione del pensiero: l'etica cristiana originaria nelle frühe Freiburger Vorlesungen di Martin Heidegger. Genova: Il Melangolo, 2010. 